\title{
Operative mortality in adult cardiac surgery: is the currently utilized definition justified?
}

\author{
Patrick G. Chan ${ }^{1}$, Laura Seese ${ }^{1}$, Edgar Aranda-Michel ${ }^{1}$, Ibrahim Sultan ${ }^{1,2}$, Thomas G. Gleason ${ }^{1,2}$, \\ Yisi Wang ${ }^{1,2}$, Floyd Thoma ${ }^{1,2}$, Arman Kilic ${ }^{1,2}$ \\ ${ }^{1}$ Division of Cardiac Surgery, Department of Cardiothoracic Surgery, University of Pittsburgh Medical Center, Pittsburgh, PA, USA; ${ }^{2}$ Heart and \\ Vascular Institute, University of Pittsburgh Medical Center, Pittsburgh, PA, USA \\ Contributions: (I) Conception and design: PG Chan, L Seese, Y Wang, A Kilic; (II) Administrative support: I Sultan, TG Gleason, A Kilic; (III) \\ Provision of study materials or patients: I Sultan; (IV) Collection and assembly of data: PG Chan, E Aranda-Michel; (V) Data analysis and \\ interpretation: PG Chan, L Seese, Y Wang, F Thoma, A Kilic; (VI) Manuscript writing: All authors; (VII) Final approval of manuscript: All authors. \\ Correspondence to: Arman Kilic, MD. Division of Cardiac Surgery, 200 Lothrop Street, Suite C700, Pittsburgh, PA 15213, USA. Email: kilica2@upmc.edu.
}

Background: This study evaluated operative mortalities following adult cardiac surgical operations to determine if this metric remains appropriate for the modern era.

Methods: This was a retrospective review of Society of Thoracic Surgeons (STS) indexed adult cardiac operations that included coronary artery bypass grafting (CABG), aortic valve replacement (AVR), CABG + AVR, mitral valve repair (MVr), CABG + MVr, mitral valve replacement (MVR) and CABG + MVR, performed at a single institution between 2011 and 2017. The primary outcome was the timing and relatedness of operation mortality, as defined by the STS as mortality within 30-day or during the index hospitalization, compared to the index operation. The secondary outcomes evaluated cause of death and the rates of postoperative complications.

Results: A total of 11,190 index cardiac operations were performed during the study period and operative mortality occurred in $246(2.2 \%)$ of patients. The distribution of operative mortalities included $83.7 \%(n=206)$ who expired within 30-day while an inpatient, $6.9 \%(\mathrm{n}=17)$ died within 30-day as an outpatient, $11.2 \%(\mathrm{n}=23)$ expired after 30-day. The most common causes of operative mortality were cardiac $(38.7 \%, \mathrm{n}=92)$, renal failure $(15.6 \%, n=37)$, and strokes $(13.9 \%, n=33)$. Furthermore, $98.4 \%(n=242)$ of deaths were attributable to the index operation. Postoperative complications occurred frequently in those with operative mortality, with blood transfusions (80.1\%), reoperations $(65.0 \%)$ and prolonged ventilation $(62.2 \%)$ being most common.

Conclusions: Most of the operative mortalities seemed to be attributable to the index cardiac operation. We believe that the current definition of mortality remains appropriate in the modern era.

Keywords: Cardiac surgery; coronary artery bypass grafting (CABG); aortic valve replacement (AVR); mitral valve repair (MVr); mitral valve replacement (MVR); operative mortality

Submitted Jun 15, 2020. Accepted for publication Dec 13, 2020.

doi: $10.21037 /$ jtd-20-2213

View this article at: https://dx.doi.org/10.21037/jtd-20-2213

\section{Introduction}

Traditionally operative mortality has been utilized as a quality measure for evaluating value-based hospital performance and determining reimbursements from insurance payers. Operative mortality initially originated in the mid 1980's with the Centers for Medicare and Medicaid
Services (CMS) releasing hospital mortality rates as an indicator for quality in healthcare and has led to insurance payer mandated hospital reporting of 30-day outcomes for all surgical procedures (1). Subsequently, the Society of Thoracic Surgeons (STS) formed the Adult Cardiac Surgery Database (ACSD) in 1989 to report outcomes for cardiac procedures, with 30-day mortality being an 
important metric guiding the evolution of cardiac operative approach (2). However, it became apparent that capturing in-hospital events and 30-day mortality alone was not truly reflective of procedural outcomes. As such, the societal guidelines expanded the mortality metric to operative mortality, which is the any death that occurred during hospitalization, irrespective of time, and any death within 30-days, independent of location (3). This change more accurately reflected the procedural outcomes and reduced the potential unethical incentives for using aggressive interventions in clinical futile situations. The ACSD has expanded its domain to include risk-prediction for operative mortality as well as risk-adjusted public reporting through the 3-star hospital rating of cardiac surgery performance (4). Although operative mortality is a long-standing metric, the question of its sufficiency for determining institutional performance measures and practice differences in cardiac surgery remains to be delineated. Also, using operative morality as a key metric may capture patients who expire from events following discharge, yet within 30-day, that are unrelated to their surgical procedures, such as motor vehicle accidents or traumatic falls. While it is well established that the patient population that incurs operative mortality tend to have more preoperative comorbidities, the exact cause of death following STS-indexed cases and the its relatedness to the surgery remain unknown. Furthermore, the timing death within operative mortality (i.e., within 30-day and inpatient, inpatient and beyond 30-day or postdischarge and within 30-day) is also unknown. The aim of this study was to enhance the understanding of the timing, systems-based cause and association of death with the index operation in patients who experienced operative mortality to determine if operative mortality remains a pertinent outcome measure in the modern era.

We present the following article in accordance with the STROBE reporting checklist (available at https://dx.doi. org/10.21037/jtd-20-2213).

\section{Methods}

\section{Study population}

This study is a retrospective review that utilizes institutionspecific data from the STS adult cardiac database supplemented with mortality data from the social security master death index file as well as additional granular data from our electronic health record. Adults undergoing STS-indexed cardiac operations including coronary artery bypass grafting (CABG), aortic valve replacement (AVR), combined CABG and AVR (CABG + AVR), mitral valve repair $(\mathrm{MVr})$, combined $\mathrm{CABG}$ and $\mathrm{MVr}(\mathrm{CABG}+\mathrm{MVr})$, mitral valve replacement (MVR) and combined CABG and MVR (CABG + MVR) between 2011 to 2017 were screened for inclusion. Other operations that did not fall into any of these categories were excluded from this study. From the 11,190 patients screened, those who incurred mortality within 100 days of the index operation were included. Both in-hospital deaths and deaths after discharge were included. The study was conducted in accordance with the Declaration of Helsinki (as revised in 2013). This study was exempt by the institutional review board at the University of Pittsburgh and consent for the study was waived.

\section{Baseline characteristics}

Baseline preoperative characteristics were evaluated. These included demographic characteristics such as age, sex and race. Comorbidities included diabetes mellitus, hypertension, chronic obstructive pulmonary disease, immunosuppression exposure, peripheral artery disease, cerebrovascular disease, cardiac symptoms at presentation, number of diseased vessels and left ventricular ejection fraction. Operative status was categorized as elective, urgent, emergent or salvage. The STS-indexed operation performed and the STS-Predicted Risk of Mortality (STSPROM) was also assessed.

\section{Outcomes}

The primary outcome was the timing and relatedness of operation mortality, as defined by the STS as mortality within 30-day or during the index hospitalization, which is the same hospitalization of the index operation. The secondary outcomes evaluated cause of death and the rates of postoperative complications. The postoperative complications that were assessed included those defined by the STS as a major morbidity: prolonged ventilation (>24 hours), blood product transfusion, new-onset renal failure, permanent stroke, pneumonia, sepsis, new-onset atrial fibrillation, deep sternal wound infection (DSWI), and all-cause reoperation. The clinical definitions for these complications were derived from the criteria set forth from the STS Adult Cardiac Surgery Database version 2.81. The systems-based cause of death was identified as cardiac, pulmonary, neurologic (specifically strokes), renal, hepatic or gastrointestinal based on the documented data extracted 
from the death certificate. If multiple systems were cited as causes of death, they were all included for comparative analysis.

\section{Data analysis}

Demographic and clinical characteristics are presented as frequency (percentage) for categorical variables and mean \pm standard deviation for Gaussian continuous variables or median [interquartile range (IQR)] for non-Gaussian continuous variables. Normality was checked with the Kolmogorov-Smirnov test. Pearson's Chi-square Test or Fisher's exact test was utilized for categorical variables and continuous variables were analyzed with $t$-tests if normally distributed and Mann Whitney $U$ test if non-Gaussian. Timing of operative mortality in relation to the index operation was assessed by stratifying the day of death into terciles, with less than 3 days as the first tercile, 4 to 18 days the second tercile and 19 or greater days the third tercile. Statistical analyses were performed using STATA version 15 software (StataCorp LLC, College Station, TX, USA).

\section{Results}

\section{Baseline characteristics}

A total of 11,190 index cardiac operations were performed during the study period including $62.8 \%(\mathrm{n}=7,048)$ isolated CABG, $15.9 \%(\mathrm{n}=1,779)$ isolated AVR, 10.6\% $(\mathrm{n}=1,185)$ CABG+AVR, 4.6\% ( $n=513)$ isolated MVr, 3.2\% ( $\mathrm{n}=356)$ $\mathrm{CABG}+\mathrm{MVr}, 1.9 \%(\mathrm{n}=215)$ isolated MVR, and $0.84 \%$ $(\mathrm{n}=94)$ CABG+MVRs. The study population consisted of 246 patients who underwent an STS-indexed operation and incurred operative mortality within the study period. The mean age was 72 years, most patients were male $(62.6 \%$; $\mathrm{n}=154)$, and $91.9 \%(\mathrm{n}=226)$ were white (Table 1). The most comorbidities were common with $82.9 \%(\mathrm{n}=204)$ of patients having dyslipidemia, 55.3\% ( $\mathrm{n}=136)$ having diabetes mellitus, 34.1\% $(\mathrm{n}=84)$ having prior cerebrovascular disease and $8.5 \%(\mathrm{n}=21)$ being dialysis dependent. On presentation, many patients experienced unstable angina $(31.7 \% ; \mathrm{n}=78)$ and had 3 -vessel coronary disease $(67.9 \%, n=167)$. The majority of patients required urgent operative intervention $(56.5 \% ; \mathrm{n}=139)$ and many had a preoperative intra-aortic balloon pump (IABP) $(34.6 \%, n=85)$. Of the 268 operative mortalities, there were 62 patients $(23.1 \%)$ who had a left ventricular ejection fraction of less than $30 \%$. The most commonly performed cardiac operation was CABG $(52.5 \%$; $\mathrm{n}=115$ ). The overall STS-PROM for our population was $11.0 \%$, with an actual percentage death of $2.4 \%$, resulting in an observed-to-expected of 4.6 (Table 2).

\section{Postoperative complications}

Postoperative complications were frequent among patients who experienced operative mortality (Table 3). In descending order of frequency blood transfusions occurred in $80.1 \%(\mathrm{n}=197)$, all-cause reoperations occurred in $65.0 \%$ $(\mathrm{n}=160)$, prolonged ventilation occurred in $62.2 \%(\mathrm{n}=153)$, renal failure requiring dialysis occurred in $30.9 \%(n=76)$ and sepsis occurred in $14.2 \%(\mathrm{n}=35)$. In addition to this, extracorporeal membrane oxygenation support was also required in $11.6 \%$ of the operative mortalities $(n=31)$.

\section{Timing and location of operative mortality}

Of the 246 operative mortality deaths, the majority died within 30-day and while still an inpatient $(83.7 \%, \mathrm{n}=206)$. There were $6.9 \%(n=17)$ who expired within 30 -day but following discharge. The remaining $11.2 \%(n=23)$ died after 30 -day on the index hospitalization. Nearly all the operative mortalities $(99.2 \%, n=242)$, including those following discharge, were related to the index operation. There were 2 patients $(0.8 \%)$ whose mortality was unrelated with one due to an intracranial hemorrhage after a ground level fall and the other due to a perforated duodenal ulcer. The terciles for the timeline of operative mortality resulted in $25.5 \%(\mathrm{n}=68)$ who expired within 3 -day, $47.2 \%(\mathrm{n}=126)$ died within 4 to 18 days, and $27.7 \%(\mathrm{n}=74)$ died after 19 days (Figure 1).

\section{Operative mortality cause of death}

The majority of operative deaths were caused by cardiac system failures and contributed to a higher incidence of death at all time intervals (Figure 2). The rates of operative deaths due to cardiac system failure decreased over time with $87.8 \%$ of deaths due to cardiac failure within 3 days of the index operation, $64.0 \%$ due to cardiac failure between 4 and 18 days, and $55.2 \%$ due to cardiac failure after 19 days $(\mathrm{P}<0.001)$. Pulmonary operative deaths were more common in the later postoperative stages, with $34.4 \%$ occurring after 4 days and $49.3 \%$ after 19 days $(\mathrm{P}<0.001)$. Strokes contributed to operative deaths at similar rates throughout follow-up with $12.2 \%$ of deaths occurring within 3 days, $20.0 \%$ occurring within 4 to 18 days, and $11.9 \%$ occurring 
Table 1 Baseline characteristics in operative mortality patients

\begin{tabular}{|c|c|}
\hline Characteristics & $\begin{array}{l}\text { Operative mortalities, } \\
\qquad N=246\end{array}$ \\
\hline Age, mean (SD) & $71.99 \pm 10.31$ \\
\hline Female & $92(37.4 \%)$ \\
\hline \multicolumn{2}{|l|}{ Race } \\
\hline Caucasian & 226 (91.9\%) \\
\hline Black & $14(5.7 \%)$ \\
\hline BMI, mean (SD) & $29.38 \pm 6.71$ \\
\hline Dyslipidemia & $204(82.9 \%)$ \\
\hline Diabetes Mellitus & $136(55.3 \%)$ \\
\hline COPD & $77(31.3 \%)$ \\
\hline Dialysis & $21(8.5 \%)$ \\
\hline Creatinine (mg/dL) & $1.60 \pm 1.50$ \\
\hline Immunosuppressed & $21(8.5 \%)$ \\
\hline Peripheral vascular disease & $86(35.0 \%)$ \\
\hline Cerebrovascular disease & $84(34.1 \%)$ \\
\hline Prior CABG & $26(26 \%)$ \\
\hline Prior PCl & $72(73 \%)$ \\
\hline Family history of CAD & $55(22.4 \%)$ \\
\hline \multicolumn{2}{|l|}{ Cardiac symptoms at presentation } \\
\hline No symptoms & $32(13.0 \%)$ \\
\hline Stable angina & $24(9.8 \%)$ \\
\hline Unstable angina & $78(31.7 \%)$ \\
\hline NSTEMI & $56(22.8 \%)$ \\
\hline STEMI & $25(10.2 \%)$ \\
\hline Angina equivalent & $16(6.5 \%)$ \\
\hline None & $15(6.1 \%)$ \\
\hline Congestive heart failure & $128(52.0 \%)$ \\
\hline Atrial fibrillation & $41(33.9 \%)$ \\
\hline \multicolumn{2}{|l|}{ Number of diseased vessels } \\
\hline 0 & $26(10.6 \%)$ \\
\hline 1 & $12(4.9 \%)$ \\
\hline 2 & $41(16.7 \%)$ \\
\hline 3 & $167(67.9 \%)$ \\
\hline Left ventricular ejection fraction (\%) & $44.25 \pm 16.47$ \\
\hline Preoperative intra-aortic balloon pump & $85(34.6 \%)$ \\
\hline
\end{tabular}

Table 1 (continued)
Table 1 (continued)

\begin{tabular}{lc}
\hline Characteristics & $\begin{array}{c}\text { Operative mortalities, } \\
\mathrm{N}=246\end{array}$ \\
\hline Operative status & $69(28.0 \%)$ \\
Elective & $139(56.5 \%)$ \\
Urgent & $36(14.6 \%)$ \\
Emergent & $2(0.8 \%)$ \\
Emergent salvage & \\
STS-indexed operation performed & $18(8.2 \%)$ \\
AVR & $34(15.5 \%)$ \\
AVR + CAB & $115(52.5 \%)$ \\
CABG & $8(3.7 \%)$ \\
MV repair & $21(9.6 \%)$ \\
MV repair + CAB & $8(3.7 \%)$ \\
MV replace & $7(3.2 \%)$ \\
MV replace + CAB & $5.8 \%(2.8-12.2 \%)$ \\
STS-PROM (\%)
\end{tabular}

AVR, aortic valve replacement; CAD, coronary artery disease; CABG, coronary artery bypass grafting; CPB, cardiopulmonary bypass; MV, mitral valve; NSTEMI, non-ST elevation myocardial infarction; PCI, percutaneous coronary intervention; STEMI, ST elevation myocardial infarction; STS-PROM, Society for Thoracic Surgeons Predicted Risk of Mortality.

after 19 days (all $\mathrm{P}>0.05$ ). Similarly, renal failure also tended to contribute to more late operative deaths as compared to early operative deaths with $12.2 \%$ within 3 days, $28.0 \%$ between 4 and 18 days and $38.8 \%$ after 19 days $(\mathrm{P}<0.001)$. Operative deaths that occurred secondary to hepatic dysfunction were rare but increased in incidence over time with $4.1 \%$ of deaths occurring within 3 days, $12.0 \%$ of deaths between 4 and 18 days and $13.4 \%$ after 19 days (all $\mathrm{P}>0.05)$. Operative deaths attributable to gastrointestinal causes were also rare but increased in frequency throughout follow-up with $5.4 \%$ within 3 days, $6.4 \%$ between 4 and 18 days and $14.9 \%$ after 19 days (all $\mathrm{P}>0.05$ ).

\section{The impact of STS-index operation on operative mortality}

\section{Isolated cardiac operations}

Approximately $52.5 \%(\mathrm{n}=115)$ of the operative mortalities occurred in patients following CABG. Operative mortalities following CABG were most commonly cardiac-related 
Table 2 Observed and expected deaths

\begin{tabular}{|c|c|c|c|c|c|c|c|c|}
\hline $\begin{array}{l}\text { Observed and } \\
\text { expected deaths }\end{array}$ & Overall & CABG & AVR & $C A B G+A V R$ & $\mathrm{MVr}$ & $\mathrm{CABG}+\mathrm{MVr}$ & MVR & $C A B G+M V R$ \\
\hline STS PROM (\%) & 11 & 10.3 & 8.9 & 9.2 & 3.4 & 15.6 & 23.3 & 16.1 \\
\hline Actual death (\%) & 2.4 & 2.1 & 1.2 & 4.2 & 1.6 & 6.5 & 4.2 & 13.0 \\
\hline $\mathrm{O} / \mathrm{E}$ & 4.6 & 4.9 & 7.4 & 2.2 & 2.1 & 2.4 & 5.6 & 1.2 \\
\hline
\end{tabular}

Table 3 Major postoperative complications in operative mortality patients

\begin{tabular}{lc}
\hline Complications & Operative mortalities, N=246 \\
\hline Blood product transfusion & $197(80.1 \%)$ \\
Stroke & $6(2.4 \%)$ \\
Prolonged ventilation (>24 hours) & $153(62.2 \%)$ \\
Reoperation (all cause) & $160(65.0 \%)$ \\
Renal failure (all) & $97(39.4 \%)$ \\
Renal failure requiring dialysis & $76(30.9 \%)$ \\
Pneumonia & $33(13.4 \%)$ \\
Sepsis & $35(14.2 \%)$ \\
Deep sternal wound infection & $4(1.6 \%)$ \\
\hline
\end{tabular}

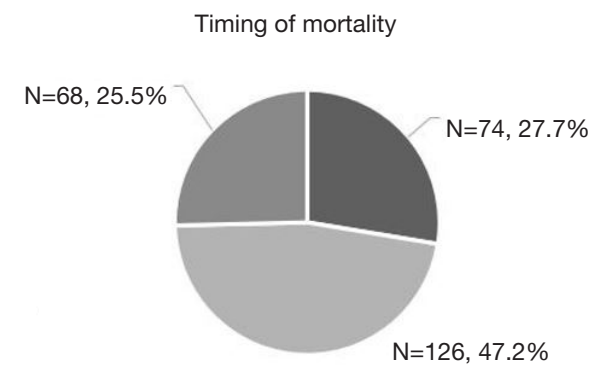

" $<25$ th Percentile (within 3 days) " 25th to 75 th Percentile (4-8 days) - >75th Percentile (19 days to more)

Figure 1 Pie chart demonstrating the timing of operative mortality.

and a significantly greater incidence of CABG operative mortalities occurred in the early postoperative period, $86.5 \%$ within 3 days compared to $61.4 \%$ between 4 and 18 days, and $62.9 \%$ after 19 days $(\mathrm{P}<0.001)$. Pulmonaryrelated operative deaths were the next most frequent, followed by renal-related operative deaths in CABG patients (Figure $3 A)$. There were $8.2 \%(\mathrm{n}=18)$ of the

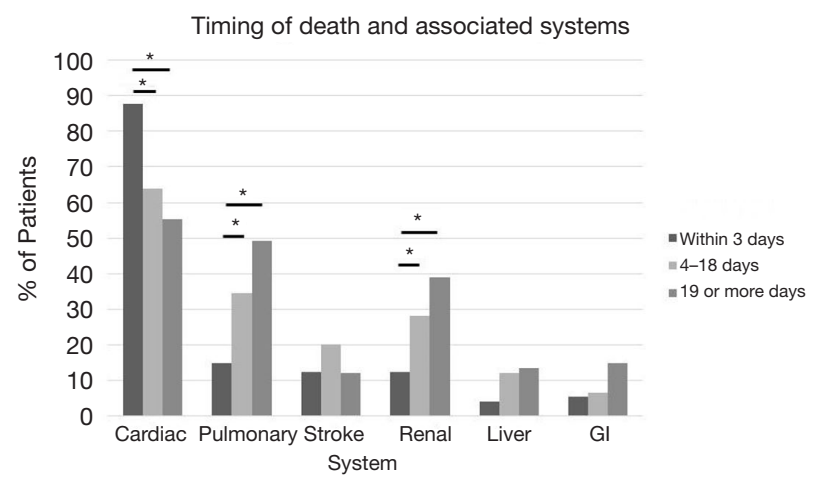

Figure 2 Bar graph demonstrating the system-related cause of operative mortality stratified by the timing of death. *, indicates statistical significance, $\mathrm{P}<0.05$.

operative deaths that occurred following AVR. These deaths were most frequently attributable to cardiac-related causes $(81.0 \%)$ and similarly occurred at significantly higher rates in the first 3 postoperative days $(80.0 \%$ within 3 days, $77.8 \%$ between 4 and 18 days and $100 \%$ greater than 19 days, $\mathrm{P}=0.04$ ) (Figure 3B). The incidence of operative deaths in the MVR and MVr group was $7.4 \%(n=16)$. In those who experienced early operative mortality, within 3 days, $100.0 \%$ had an aspect of cardiac-system failure. Deaths attributed to pulmonary, stroke and renal failure occurred exclusively after 3 days in those who underwent MVR or MVr. There were no significant differences between time points of mortality with pulmonary, stroke or renal components ( $0 \%$ vs. $37.5 \%$ vs. $40.0 \%, 0 \%$ vs. $50.0 \%$ vs. $40.0 \%$, and $0 \%$ vs. $12.5 \%$ vs. $40.0 \%$, respectively) (Figure 4 ).

\section{Combined cardiac operations}

Operative mortalities occurred in $15.5 \%(n=34)$ of those who underwent CABG+AVR. Deaths attributable to cardiac factors were twice as likely in the first 3 postoperative days compared to after 19 days $(92.7 \%$ vs. $73.7 \%$ vs. $41.2 \%, \mathrm{P}<0.001)$. Furthermore, the incidence of pulmonary, renal, and stroke-related deaths increased temporally throughout follow-up, although these increases 

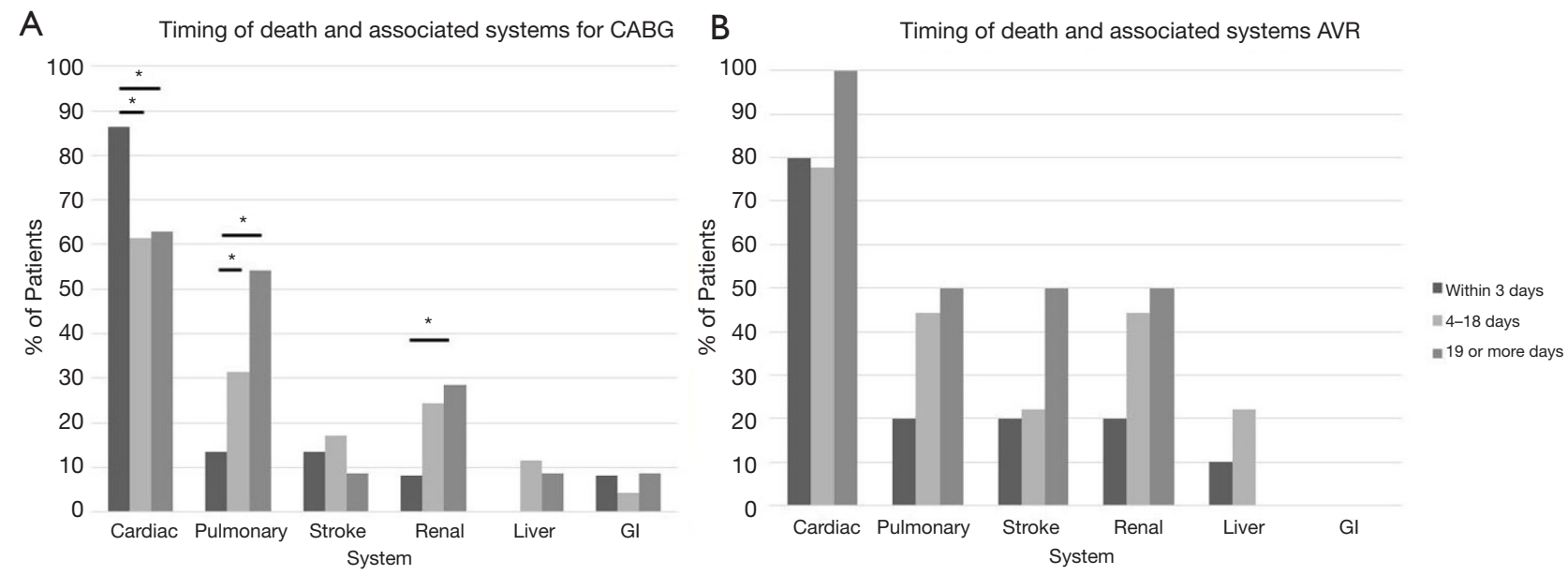

Figure 3 Bar graphs demonstrating the systems-related cause of death. Panel (A) demonstrates timing of death for CABG. Panel (B) demonstrates timing of death for AVR. *, indicates statistical significance $\mathrm{P}<0.05$. CABG, coronary artery bypass grafting; AVR, aortic valve replacement.

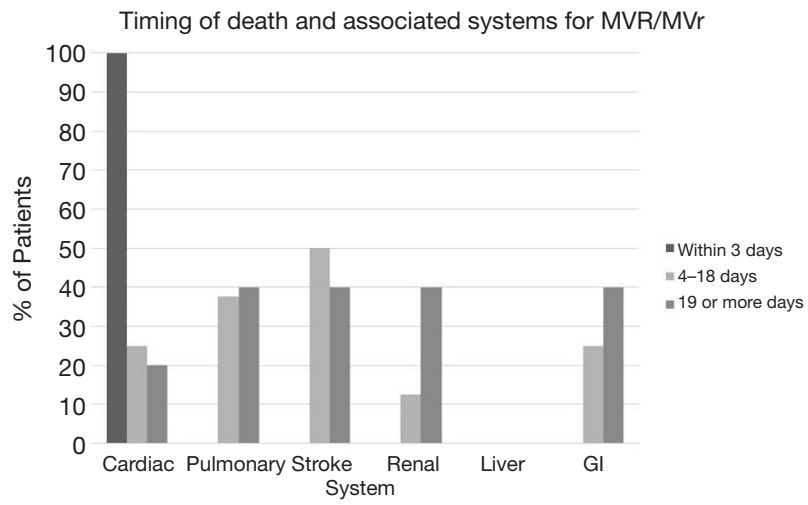

Figure 4 Bar graph demonstrating the system-related cause of operative mortality stratified by timing in MVR and MVr patients. MVR, mitral valve replacement; $M V r$, mitral valve repair.

did not achieve statistical significance (Figure $5 A$ ). Patients who underwent combined CABG + MVR or MVr comprised $7.0 \%(n=34)$ of the operative mortalities. Again, a majority of operative mortalities within this group were cardiac-related $(77.1 \%)$ and most of the cardiac-related deaths occurred within the first 3 postoperative days ( $77.1 \%$ vs. $73.7 \%$ vs. $41.2 \%, \mathrm{P}=0.18$ ) (Figure $5 B$ ). There were also increases in the occurrence of pulmonary-related and renal-related over time, although these were not statistically significant.

\section{Discussion}

The STS has defined operative mortality as "(I) all deaths occurring during the acute episode of hospitalization in which the operation was performed (this includes patients transferred to other acute facilities), even if after 30-day; and (II) deaths occurring after discharge but within 30-day of the procedure, regardless of cause (3)." While operative mortality is a frequently reported postoperative event in cardiac surgery research and public reporting, the exact composition of the timeframe, location, relatedness to the index operation and causes of operative deaths remain elusive. Many have suggested that a 30-day timeframe may not be sufficient to adequately evaluate mortality; however, prior to instituting a more prolonged interval for operative mortality evaluation, establishing if the current definition of operative mortality is sufficient for patients in the modern era is prudent. The aim of this study was to enhance the understanding of the timing, systems-based cause and association of death with the index operation in patients who experienced operative mortality to determine if the current definitions of operative mortality remains an adequate measure in the modern era.

\section{Study findings}

The primary finding of our analysis was that over $95 \%$ 

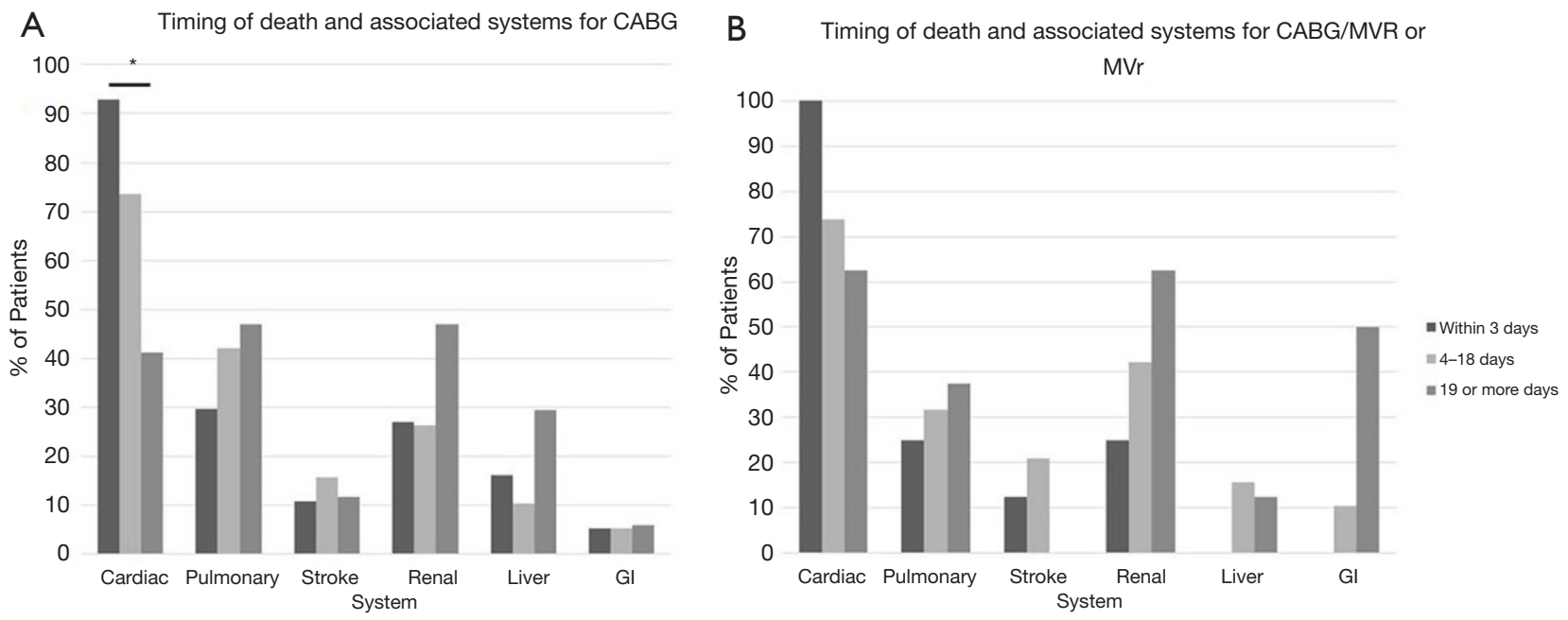

Figure 5 Bar graphs demonstrating the timing for the systems-related cause of death. Panel (A) demonstrates timing of death for combined coronary artery bypass grafting with aortic valve replacement. Panel (B) shows timing of death for coronary artery bypass grafting with mitral valve repair or replacement. *, indicates statistical significance $\mathrm{P}<0.05$.

of the operative mortalities in our cohort were related to cardiac operation. In the modern era, with better clinical protocols and more patients being discharged early on in their hospitalization, concern exists that external factors such motor vehicle accidents, medication overdoses or traumatic injuries may increase the risk for operative mortality after patients return home. Considering that only $0.8 \%$ of our patients experienced operative mortalities that were unrelated to their index operative suggests that the majority of patients are being accurately captured. Contradistinctively, others have suggested that using operative mortality as a metric for public reporting may potentially delay the withdrawal of life-saving strategies for unsalvageable patients or potentially encourage the discharge of critically ill patients to non-acute care settings that may be ill-equipped to handle their clinical condition. When evaluating the system-based contributions to cause of death, the prevalent contributions to operative mortality were from cardiac failure, which occurred most frequently in the early postoperative period within the first 3 postoperative days. The specific events leading up to operative morality due to cardiac-system failure were malignant arrhythmias, postoperative cardiac arrests, inability to separate from cardiopulmonary bypass intraoperatively, and thrombosed bypass grafts after CABG. These findings are consistent with prior studies showing that a majority of CABG deaths involved the cardiovascular system $(5,6)$. Most recently, Butt and colleagues reviewed the Danish national registry from 1998-2014 for patients undergoing CABG, reviewing over 12,000 deaths. The studied determined that a majority of the deaths were cardiovascular related (52.8\%) (5). Similarly, Drye and colleagues performed a prospective study with 8,631 patients that included 384 deaths which showed a majority of CABG deaths were attributed to heart failure (6). Following cardiac-related deaths, pulmonary-related and then renal-related causes of death were the next most frequent. When operative mortality was attributable to pulmonary-related or renal-related causes, these events tended to occur later in the postoperative period, after 19 days. Collectively, this data suggests that operative mortality is an adequate measure of early mortality attributable to cardiac operations. In addition, there is an advantage of using STS-PROM as well, as this mortality score is updated frequently to reflect the latest nuances in calculating predicted mortality.

\section{Prior studies evaluating the adequacy of operative mortality as a metric}

Understanding the utility of operative mortality as a quality measure in the context of cardiac surgery is essential given the close relationships between quality of patients care and hospital reimbursements. Although there is a paucity of evidence evaluating the composition and adequacy of operative mortality, there are several studies that have 
evaluated the potential shortfalls of using the 30-day aspect of the STS definition in isolation. Maximus et al. utilized the California Office of Statewide Health Planning and Development hospitalized patient discharge database to evaluate 5 different methods of mortality reporting for cardiac surgical procedures and percutaneous coronary interventions (7). The authors found that only $4 \%$ of operative mortalities occurred post-discharge and that the current STS definition of operative mortality captured the highest rate of mortalities, although statistical significance was not assessed. They also suggested that extending operative mortality to include the post-discharge period, regardless of location, was important to remove any incentive for unethically prolonging the life of a dying patient past the 30-day cutoff or transferring a medically futile patient to another facility to avoid a mortality. Hua and colleagues retrospectively evaluated if there was a rise in mortality immediately following 30-day, which may suggest that delays in the withdrawal of life-sustaining care in clinically futile patients and found no evidence of increases in mortality rates during that timeframe (8). The authors suggested that based on these findings that this practice does not routinely occur in cardiac surgery. In a recent analysis of 30,329 transcatheter aortic valve replacements and 26,021 surgical AVRs, 30-day mortality underestimated adjusted hospital performance outcomes when compared to 90-day mortality (9). Additionally, the authors found a plateau in the instantaneous hazard for mortality after 90-day suggesting that capturing 90-day events was more reflective of 1 -year outcomes. Several other non-cardiac surgical studies have also found that 30-day mortality overestimates hospital quality of care and 90-day mortality may be a more accurate representation of surgery-related deaths $(10,11)$. Considering that only $6.9 \%$ of patients in our study expired following discharge within the 30-day period, these questions if the full STS definition of operative mortality had been assessed if such wide conversion rates between 30- and 90-day mortality would have been observed. A multi-institutional, retrospective analysis from the Netherlands evaluated if mortality assessments should be extended to longer time periods of follow-up (12). The analysis demonstrated that the survival curves had a steep initial decline up until 60-day and depending on the index case they stabilized between 60 to 120 days suggesting that an appropriate mortality measure in this cohort may be at 4-month follow-up. Even though longer periods for assessing operative mortality may result in more accurate representations of hospital performance, the current 30-day mortality variable tracked by the STS has been shown to have up to $22 \%$ missing data (13). This suggests that more robust methods of post-discharge tracking may need to be implemented prior to any proposed extensions of the morality assessment period.

The intent of this study was not to determine if more longitudinal follow-up would capture higher rates of mortalities or be more reflective of longer-term outcomes, but instead to investigate if the operative mortality, as defined by the STS, captured the intended mortalities that were associated with the index operation. However, it appears that while the current definition of operative mortality captures the intended population of mortalities, there may be benefit in extending the follow-up period for patients who are discharged from the hospital to 90-day. This obviously comes with a follow-up burden for patients who do not return for postoperative visits or receive care through different health systems. Moreover, a 90-day metric is more congruent with the current CMS, Bundled Payments for Care Improvement initiative where hospitals are responsible for all costs from the time of the index procedure to 90-day follow-up (14). If the STS replaces the 30 -day aspect of the operative mortality definition with a 90-day assessment, future studies will be needed to ensure that the intended mortalities are still being captured.

\section{Limitations}

Foremost, this is a single center, retrospective study with the inherent limitations of its design as well as unclear generalizability to other centers. The death pronouncements and certificates from which the cause of death data was obtained were inconsistent in their specificity of the exact timing and causes of death. Additionally, several patients ultimately expired when the decision to withdrawal care was implemented by their families. There is variation in the practice patterns of clinicians and the timing of family discussions that could not be accounted for and this may have influenced the timing of operative mortalities.

In conclusion, our study shows that the current definition STS definition of operative mortality sufficiently captures the intended mortalities, with over $95 \%$ being directly related to the operative intervention. Additionally, the majority of operative deaths are caused by cardiac system failure and this occurs early in the first 3 postoperative days. Deaths that had a pulmonary, renal and GI component were more likely to occur at the later time points. While this study supports the accuracy of operative mortality as it 
is currently defined, future studies are needed to evaluate if extending the follow-up to 90-day while still utilizing the other aspects of operative mortality would improve the evaluation of hospital performance.

\section{Acknowledgments}

Funding: None.

\section{Footnote}

Reporting Checklist: The authors have completed the STROBE reporting checklist. Available at https://dx.doi. org/10.21037/jtd-20-2213

Peer Review File: Available at https://dx.doi.org/10.21037/ jtd-20-2213

Data Sharing Statement: Available at https://dx.doi. org/10.21037/jtd-20-2213

Conflicts of Interest: All authors have completed the ICMJE uniform disclosure form (available at https://dx.doi. org/10.21037/jtd-20-2213). TGG reports that he is on the Medical Advisory Board at Abbott, but this does not pose a potential conflicts of interest. AK reports that he is on the Medical Advisory Board at Medtronic, but this does not pose a potential conflicts of interest. The other authors have no conflicts of interest to declare.

Ethical Statement: The authors are accountable for all aspects of the work in ensuring that questions related to the accuracy or integrity of any part of the work are appropriately investigated and resolved. The study was conducted in accordance with the Declaration of Helsinki (as revised in 2013). This study was exempt by the institutional review board at the University of Pittsburgh and consent for the study was waived.

Open Access Statement: This is an Open Access article distributed in accordance with the Creative Commons Attribution-NonCommercial-NoDerivs 4.0 International License (CC BY-NC-ND 4.0), which permits the noncommercial replication and distribution of the article with the strict proviso that no changes or edits are made and the original work is properly cited (including links to both the formal publication through the relevant DOI and the license). See: https://creativecommons.org/licenses/by-nc-nd/4.0/.

\section{References}

1. Wang DE, Tsugawa Y, Figueroa JF, et al. Association Between the Centers for Medicare and Medicaid Services Hospital Star Rating and Patient Outcomes. JAMA Intern Med 2016;176:848-50.

2. Jacobs JP, Shahian DM, Prager RL, et al. Introduction to the STS National Database Series: Outcomes Analysis, Quality Improvement, and Patient Safety. Ann Thorac Surg 2015;100:1992-2000.

3. Overman DM, Jacobs JP, Prager RL, et al. Report from the Society of Thoracic Surgeons National Database Workforce: clarifying the definition of operative mortality. World J Pediatr Congenit Heart Surg 2013;4:10-2.

4. Shahian DM, Jacobs JP, Badhwar V, et al. Risk Aversion and Public Reporting. Part 1: Observations From Cardiac Surgery and Interventional Cardiology. Ann Thorac Surg 2017;104:2093-101.

5. Butt JH, Sørensen R, Bäck C, et al. Short- and long-term cause of death in patients undergoing isolated coronary artery bypass grafting: A nationwide cohort study. J Thorac Cardiovasc Surg 2018;156:54-60.e4.

6. Drye EE, Normand SL, Wang Y, et al. Comparison of hospital risk-standardized mortality rates calculated by using in-hospital and 30-day models: an observational study with implications for hospital profiling. Ann Intern Med 2012;156:19-26.

7. Maximus S, Milliken JC, Danielsen B, et al. Defining operative mortality: Impact on outcome reporting. J Thorac Cardiovasc Surg 2016;151:1101-7.

8. Hua M, Scales DC, Cooper Z, et al. Impact of Public Reporting of 30-day Mortality on Timing of Death after Coronary Artery Bypass Graft Surgery. Anesthesiology 2017;127:953-60.

9. Hirji S, McGurk S, Kiehm S, et al. Utility of 90-Day Mortality vs 30-Day Mortality as a Quality Metric for Transcatheter and Surgical Aortic Valve Replacement Outcomes. JAMA Cardiol 2020;5:156-65.

10. Koeckert MS, Grossi EA, Vining PF, et al. Ninety-Day Readmissions of Bundled Valve Patients: Implications for Healthcare Policy. Semin Thorac Cardiovasc Surg 2019;31:32-7.

11. Mise Y, Vauthey JN, Zimmitti G, et al. Ninety-day Postoperative Mortality Is a Legitimate Measure of Hepatopancreatobiliary Surgical Quality. Ann Surg 2015;262:1071-8.

12. Siregar S, Groenwold RH, de Mol BA, et al. Evaluation of cardiac surgery mortality rates: 30-day mortality or longer 
follow-up? Eur J Cardiothorac Surg 2013;44:875-83.

13. Ring WS, Edgerton JR, Herbert $M$, et al. Impact of Accurate 30-Day Status on Operative Mortality: Wanted Dead or Alive, Not Unknown. Ann Thorac Surg 2017;104:1987-93.

Cite this article as: Chan PG, Seese L, Aranda-Michel E, Sultan I, Gleason TG, Wang Y, Thoma F, Kilic A. Operative mortality in adult cardiac surgery: is the currently utilized definition justified? J Thorac Dis 2021;13(10):5582-5591. doi: $10.21037 /$ jtd-20-2213
14. Center for Medicare and Medicaid Innovation. Bundled Payments for Care Improvement (BPCI) Initiative. Available online: https://innovation.cms.gov/initiatives/ bundled-payments/. Accessed December 18, 2019. 